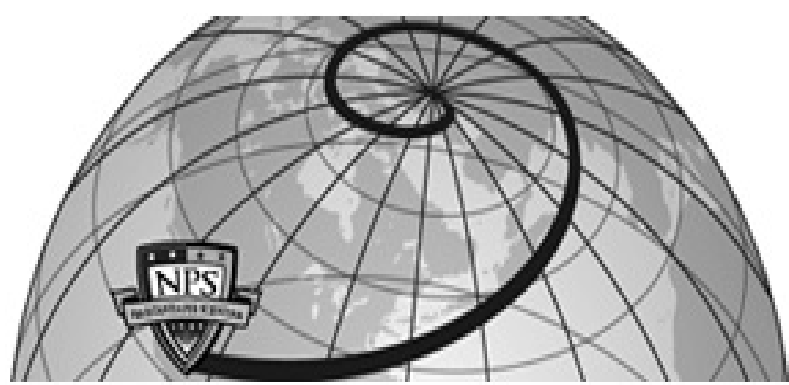

Calhoun: The NPS Institutional Archive DSpace Repository

\title{
Surge Motion Parameter Identification for the NPS Phoenix AUV
}

Marco, D. B.; Healey, A. J.

Marco, D. B., Healey, A. J., "Surge Motion Parameter Identification for the NPS Phoenix AUV", Proceedings International Advanced Robotics Program IARP 98, University of South Louisiana, February 18, 1998, pp. 197 - 210

https://hdl.handle.net/10945/36058

This publication is a work of the U.S. Government as defined in Title 17, United States Code, Section 101. Copyright protection is not available for this work in the United States.

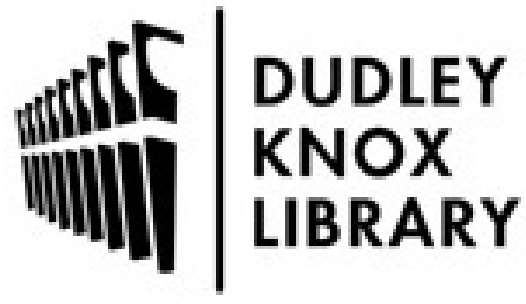

http://www.nps.edu/library
Calhoun is the Naval Postgraduate School's public access digital repository for research materials and institutional publications created by the NPS community. Calhoun is named for Professor of Mathematics Guy K. Calhoun, NPS's first appointed -- and published -- scholarly author.

\section{Dudley Knox Library / Naval Postgraduate School} 411 Dyer Road / 1 University Circle Monterey, California USA 93943 


\title{
Surge Motion Parameter Identification for the NPS Phoenix AUV
}

\author{
David B. Marco \\ Naval Postgraduate School \\ Center for AUV Research \\ Monterey, CA \\ Alfredo Martins \\ University of Porto \\ Porto, Portugal \\ Anthony J. Healey \\ Naval Postgraduate School \\ Center for AUV Research \\ Monterey, CA
}

\begin{abstract}
Recent interest in underwater vehicle maneuvering and control in shallow water has generated a need for greater understanding of vehicle dynamics in this region. Specifically, improved vehicle models and control methodologies are required for acceptable control performance in the presence of wave induced disturbances. In this paper a method for identifying the decoupled surge motion dynamic parameters of a small Autonomous Underwater Vehicle (AUV) is given. The identification is based on experimental data obtained from in-water tests of the vehicle along with post processing of the data using Kalman filtering techniques. Various lumped parameter system models of the surge dynamics are proposed and comparisons are made between them with the actual motion measurements. Identification of the square law velocity, square law propeller speed coefficients, and any first order force lag time constants is performed, as well as selection of the most appropriate model design for the experimental conditions. Since a continuously changing surge motion is required for adequate parameter identification, the vehicle is placed in a test tank and commanded to oscillate in the longitudinal direction using the stern propulsors. A series of experiments are performed with different sets of commanded oscillation amplitudes and frequencies of motion. Surge position and rate feedback for the vehicle controller is provided by an onboard high frequency sonar aimed perpendicular to one of the tank walls. A by-product of the in-water experiments is the observation of the vehicle surge performance in wave like conditions. In shallow water, the vehicle surge motion is particularly pronounced and the design of the experiment allows for the controller performance bandwidth to be studied for the specific propulsor installed. With this information and knowledge of the ocean wave conditions in certain areas, the vehicle control performance may be predicted with some degree of accuracy.
\end{abstract}

\section{INTRODUCTION}

Modeling of autonomous underwater vehicles (AUV's) has lead to the development of rather complicated equations of motion found in Fossen [1, 2] and Healey [3]. Apart from the non-linearity inherent with the motion of the vehicle, the hydrodynamic forces and moments acting on an AUV are usually modeled by a combination of theoretical and experimental results. Simpler models that describe only particular aspects of the vehicle dynamics are often needed [4], [5], and [6]. In particular, there is the need for models describing the decoupled motion of underwater vehicles. Healey $[3$, 5], suggested the possibility of decoupling the dynamic equations of motion in three independent sets regarding flight speed, steering, and dive motion control.

An important use for the models identified is the ability to develop more sophisticated control methodologies in uncertain ocean environments. The severe and unpredictable surf zone environment and absence of a human supervisor leads to the necessity for increased controller robustness for a high degree of autonomy.

Section two presents three different dynamic models of increasing complexity for describing the vehicle, while section three introduces the parameter estimation methodology using Kalman filtering techniques. The fourth Section briefly describes the in-water experimental setup for data collection. This is followed in Section five by a detailed parameter estimation analysis from the in-water test series. Section six presents a comparative analysis of each model proposed against the experimental data obtained. The final Section contains the conclusions and future directions for this work. 


\section{Report Documentation Page}

Public reporting burden for the collection of information is estimated to average 1 hour per response, including the time for reviewing instructions, searching existing data sources, gathering and maintaining the data needed, and completing and reviewing the collection of information. Send comments regarding this burden estimate or any other aspect of this collection of information, including suggestions for reducing this burden, to Washington Headquarters Services, Directorate for Information Operations and Reports, 1215 Jefferson Davis Highway, Suite 1204, Arlington VA 22202-4302. Respondents should be aware that notwithstanding any other provision of law, no person shall be subject to a penalty for failing to comply with a collection of information if it does not display a currently valid OMB control number.

\begin{tabular}{|c|c|c|}
\hline $\begin{array}{l}\text { 1. REPORT DATE } \\
\mathbf{2 0 0 5}\end{array}$ & 2. REPORT TYPE & $\begin{array}{l}\text { 3. DATES COVERED } \\
\text { - }\end{array}$ \\
\hline \multirow{3}{*}{\multicolumn{2}{|c|}{$\begin{array}{l}\text { 4. TITLE AND SUBTITLE } \\
\text { Surge Motion Parameter Identification for the NPS Phoenix AUV }\end{array}$}} & 5a. CONTRACT NUMBER \\
\hline & & 5b. GRANT NUMBER \\
\hline & & 5c. PROGRAM ELEMENT NUMBER \\
\hline \multirow{3}{*}{\multicolumn{2}{|c|}{ 6. AUTHOR(S) }} & 5d. PROJECT NUMBER \\
\hline & & 5e. TASK NUMBER \\
\hline & & 5f. WORK UNIT NUMBER \\
\hline \multicolumn{2}{|c|}{$\begin{array}{l}\text { 7. PERFORMING ORGANIZATION NAME(S) AND ADDRESS(ES) } \\
\text { Naval Postgraduate School,Center for AUV } \\
\text { Research,Monterey,CA,93943-5000 }\end{array}$} & $\begin{array}{l}\text { 8. PERFORMING ORGANIZATION } \\
\text { REPORT NUMBER }\end{array}$ \\
\hline \multirow{2}{*}{\multicolumn{2}{|c|}{ 9. SPONSORING/MONITORING AGENCY NAME(S) AND ADDRESS(ES) }} & 10. SPONSOR/MONITOR'S ACRONYM(S) \\
\hline & & $\begin{array}{l}\text { 11. SPONSOR/MONITOR'S REPORT } \\
\text { NUMBER(S) }\end{array}$ \\
\hline
\end{tabular}

12. DISTRIBUTION/AVAILABILITY STATEMENT

Approved for public release; distribution unlimited

13. SUPPLEMENTARY NOTES

The original document contains color images.

14. ABSTRACT

Recent interest in underwater vehicle maneuvering and control in shallow water has generated a need for greater understanding of vehicle dynamics in this region. Specifically, improved vehicle models and control methodologies are required for acceptable control performance in the presence of wave induced disturbances. In this paper a method for identifying the decoupled surge motion dynamic parameters of a small Autonomous Underwater Vehicle (AUV) is given. The identification is based on experimental data obtained from in-water tests of the vehicle along with post processing of the data using Kalman filtering techniques. Various lumped parameter system models of the surge dynamics are proposed and comparisons are made between them with the actual motion measurements. Identification of the square law velocity, square law propeller speed coefficients, and any first order force lag time constants is performed, as well as selection of the most appropriate model design for the experimental conditions. Since a continuously changing surge motion is required for adequate parameter identification, the vehicle is placed in a test tank and commanded to oscillate in the longitudinal direction using the stern propulsors. A series of experiments are performed with different sets of commanded oscillation amplitudes and frequencies of motion. Surge position and rate feedback for the vehicle controller is provided by an onboard high frequency sonar aimed perpendicular to one of the tank walls. A by-product of the in-water experiments is the observation of the vehicle surge performance in wave like conditions. In shallow water, the vehicle surge motion is particularly pronounced and the design of the experiment allows for the controller performance bandwidth to be studied for the specific propulsor installed. With this information and knowledge of the ocean wave conditions in certain areas, the vehicle control performance may be predicted with some degree of accuracy. 


\begin{tabular}{|c|c|c|c|c|c|}
\hline \multicolumn{3}{|c|}{ 16. SECURITY CLASSIFICATION OF: } & \multirow{2}{*}{$\begin{array}{l}\text { 17. LIMITATION OF } \\
\text { ABSTRACT }\end{array}$} & \multirow{2}{*}{$\begin{array}{c}\text { 18. NUMBER } \\
\text { OF PAGES } \\
\mathbf{1 7}\end{array}$} & \multirow{2}{*}{$\begin{array}{l}\text { 19a. NAME OF } \\
\text { RESPONSIBLE PERSON }\end{array}$} \\
\hline $\begin{array}{c}\text { a. REPORT } \\
\text { unclassified }\end{array}$ & $\begin{array}{c}\text { b. ABSTRACT } \\
\text { unclassified }\end{array}$ & $\begin{array}{c}\text { c. THIS PAGE } \\
\text { unclassified }\end{array}$ & & & \\
\hline
\end{tabular}

Standard Form 298 (Rev. 8-98) Prescribed by ANSI Std Z39-18 


\section{VEHICLE MODELING}

\section{A. Simplified Longitudinal Dynamics Models}

If it is assumed that the hydrodynamic forces in the surge direction are due mainly to drag and added mass, and that the thrust forces are determined by the propeller alone, a simple dynamic model for the vehicle can be derived. From the complete set of equations of motion [2] and [7] the simplified surge (longitudinal direction) dynamics equation of motion becomes

$$
\begin{aligned}
m \dot{u}(t)= & \mathrm{X}_{\dot{u}} \dot{u}(t)+\mathrm{X}_{u} u(t)|u(t)| \\
& +\mathrm{X}_{\text {prop }}(t)
\end{aligned} .
$$

The coefficient $m$ is the vehicle "dry mass", $X_{\dot{u}}$ is the longitudinal "added mass", and $\dot{u}(t)$ and $u(t)$ are the longitudinal acceleration and velocity respectively. The force due to the propeller $\mathrm{X}_{\text {prop }}(t)$, depends on two terms: the thrust force with no longitudinal velocity (Bollard pull) and a thrust loss term due to vehicle forward velocity given by

$$
\begin{aligned}
\mathrm{X}_{\text {prop }}(t)= & X_{\text {prop }_{B}} n(t)|n(t)| \\
& -\left(X_{\text {prop }_{L}}|n(t)|\right) u(t)
\end{aligned} .
$$

If the steering control of the vehicle is fixed, so that only longitudinal motions are allowed, the following equation of motion can be derived from (1) and (2) such that

$$
\begin{aligned}
\dot{u}(t)= & \mathrm{X}_{1} u(t)|u(t)|+\mathrm{X}_{2}|n(t)| u(t) \\
& +\mathrm{X}_{3} n(t)|n(t)|
\end{aligned}
$$

The model described by (3) depends on three terms, one quadratic in $u(t)$ caused by the dynamics of the body, another quadratic form in $n(t)$ (revolutions/sec of the propeller) and one cross term in $u(t)$ and $n(t)$ caused by the loss of thrust due to the longitudinal velocity $u(t)$.

However, various studies by Yoerger [8], McLean [9], and Brown [10] have shown the existence of non-linearities that are modeled as force lags in the propulsion system. Using (3) and assuming the existence of a generalized force delay, $\zeta(t)$, specified by time constant $\tau$, two new differential equations describing the system can be formulated as

$$
\dot{u}(t)=\alpha u(t)|u(t)|+\gamma u(t)|n(t)|+\zeta(\mathrm{t})
$$

where

$$
\dot{\zeta}(\mathrm{t})=-\frac{1}{\tau} \zeta(\mathrm{t})+\frac{\beta}{\tau} n(t)|n(t)|,
$$

and the units of the coefficients are $\alpha[=] 1 / L, \beta$ [=] $L / \mathrm{rev}^{2}, \gamma[=] 1 / \mathrm{rev}^{2}$, and $\tau$ [=] $T$.

The model described by (4) and (5) is in continuous time but the control and estimation is done in discrete time, so a digital model for identification purposes must be obtained. A zero order hold filter with sampling period $T$ can be used leading to the following,

$$
u_{k+1}=u_{k}+T\left(\alpha u_{k}\left|u_{k}\right|+\gamma u_{k}\left|n_{k}\right|+\zeta_{k}\right)
$$

and

$$
\zeta_{k+1}=\zeta_{k}+T\left(-\frac{1}{\tau} \zeta_{k}+\frac{\beta}{\tau} n_{k}\left|n_{k}\right|\right)
$$

\section{B. Parameter Identification Models}

The model described in the previous section has four unknown parameters that can be determined by experimental means. The variables available for measurement are $u(t)$ and $n(t)$. It is very convenient to write the model in terms of the parameters and the measurable variables only. Fortunately, increasing the order of (6) by one now results in an equation in terms of $u_{k+2}$ and $\zeta_{k+1}$. Defining a change of variable

$$
b=\frac{\beta}{\tau}
$$

and

$$
c=\frac{1}{\tau}
$$

a second order model in $u$ is as follows

$$
\begin{aligned}
u_{k+2} & =2 u_{k+1}-u_{k}+T \alpha\left(u_{k+1}\left|u_{k+1}\right|-u_{k}\left|u_{k}\right|\right) \\
& +T c\left(u_{k}-u_{k+1}\right)+T^{2} c \alpha\left(u_{k}\left|u_{k}\right|\right) \\
& +T^{2} b\left(n_{k}\left|n_{k}\right|\right)+T \gamma\left(u_{k+1}\left|n_{k+1}\right|-u_{k}\left|n_{k}\right|\right) \\
& +T^{2} c \gamma\left(u_{k}\left|n_{k}\right|\right)
\end{aligned}
$$

Unfortunately, the model is non-linear in the parameters, however we can consider a change of 
variables to produce a linear one as a function of the new parameters by defining

$$
\begin{array}{ll}
h_{1}=u_{k+1}\left|u_{k+1}\right|-u_{k}\left|u_{k}\right| & C_{1}=T \alpha \\
h_{2}=u_{k}-u_{k+1} & C_{2}=T c \\
h_{3}=u_{k}\left|u_{k}\right| & C_{3}=T^{2} c \alpha \\
h_{4}=n_{k}\left|n_{k}\right| & C_{4}=T^{2} b \\
h_{5}=u_{k+1}\left|n_{k+1}\right|-u_{k}\left|n_{k}\right| & C_{5}=T \gamma \\
h_{6}=u_{k}\left|n_{k}\right| & C_{6}=T^{2} c \gamma
\end{array}
$$

and

$$
\begin{aligned}
& z=u_{k+2}-2 u_{k+1}+u_{k} \\
& \boldsymbol{h}=\left[\begin{array}{llllll}
h_{1} & h_{2} & h_{3} & h_{4} & h_{5} & h_{6}
\end{array}\right] \\
& \boldsymbol{\theta}=\left[\begin{array}{llllll}
C_{1} & C_{2} & C_{3} & C_{4} & C_{5} & C_{6}
\end{array}\right]
\end{aligned}
$$

The above can now be written in matrix notation as

$$
z=h \theta
$$

The parameter vector $\theta$ contains six parameters but only four are of interest caused by the nonlinearity of the original model (10) with the terms in $c \gamma$ and $c \alpha$. Equation (12) will be used to identify the parameter vector and in this case two extra degrees of freedom are present which will decrease the accuracy of the estimation for the other parameters. These two extra terms define implicit relationships between the other parameters of the model, and in the estimation process this relationship was let free, and the estimator was used to determine all six parameters.

\section{Simplification of the Identification Models}

In the identification procedure two other models were considered obtained from (4) and (5) by assuming some simplifications. The first is given by assuming no lag in the thrust force and no cross relation between $u(t)$ and $n(t)$, thus the following models are defined

Model I:

$$
\dot{u}(t)=\alpha u(t)|u(t)|+\beta n(t)|n(t)|
$$

In the second model, only the cross term $\gamma$ is assumed zero yielding

Model II:

$$
\dot{u}(t)=\alpha u(t)|u(t)|+\zeta(t)
$$

and

$$
\dot{\zeta}(t)=-\frac{1}{\tau} \zeta(t)+\frac{\beta}{\tau} n(t)|n(t)| .
$$

Model I has the advantage of already being linear in the original parameters with no extra degrees of freedom, although due to this simplicity, it may less exact in describing the actual system. Model II has three parameters for identification and for future reference the model given in the previous section using all coefficients $\alpha, \beta, \gamma$, and $\tau$ will denoted as Model III.

\section{PARAMETER ESTIMATION METHODOLOGY}

\section{A. Kalman Filter Estimator}

Various estimation methods are available for determining $\boldsymbol{\theta}$, but a preference was given to recursive algorithms due to their suitability in realtime implementations. A recursive Kalman filter was chosen for the parameter estimation since it is similar to weighted least-squares algorithms [11], and allows for the consideration of modeling and measurement errors.

For system identification, the state vector is the parameter vector $\boldsymbol{\theta}$, with the dynamics described in discrete time by:

$$
\begin{gathered}
\boldsymbol{\theta}_{k+1}=\boldsymbol{\Phi} \boldsymbol{\theta}_{k}+\Gamma \boldsymbol{w} \\
\boldsymbol{z}_{k+1}=\boldsymbol{h}_{k} \boldsymbol{\theta}_{k}+\boldsymbol{v} .
\end{gathered}
$$

The modeling noise $\boldsymbol{w}$ is considered white and Gaussian with an associated covariance matrix $\boldsymbol{Q}$, and the measurement noise is denoted by $v$ with covariance matrix $\boldsymbol{R}$. Matrix $\Phi$ describes the dynamics and is null since the system parameters are assumed to be time invariant. The measurement vector $\boldsymbol{h}_{k}$ is a time dependent function of the inputs $u(t)$ and $n(t)$. The Kalman filter equations as given by Gelb [12] are shown below.

\section{Prediction step:}

$$
\begin{gathered}
\overline{\boldsymbol{\theta}}_{k+1}=\boldsymbol{\Phi} \hat{\boldsymbol{\theta}_{k}} \\
\overline{\boldsymbol{P}}_{k+1}=\boldsymbol{\Phi} \boldsymbol{P}_{k} \boldsymbol{\Phi}^{T}+\Gamma \boldsymbol{Q} \Gamma
\end{gathered}
$$


Correction step:

$$
\begin{gathered}
\hat{\boldsymbol{\theta}_{k+1}}=\overline{\boldsymbol{\theta}}_{k+1}+\boldsymbol{L}_{k}\left(z_{k+1}-\boldsymbol{h}_{k} \overline{\boldsymbol{\theta}}_{k+1}\right) \\
\boldsymbol{P}_{k+1}=\left[\boldsymbol{I}-\boldsymbol{L}_{k} \boldsymbol{h}_{k}\right] \overline{\boldsymbol{P}}_{k+1} \\
\boldsymbol{L}_{k}=\boldsymbol{P}_{k} \boldsymbol{h}_{k}^{T}\left[\boldsymbol{h}_{k} \overline{\boldsymbol{P}}_{k} \boldsymbol{h}_{k}^{T}+\boldsymbol{R}\right]
\end{gathered}
$$

\section{B. Two-Stage Parameter Estimation}

Of the above, the parameter most easily identifiable is $\beta$ (that can be seen in the results in the next section), since it is the direct gain of propeller revolutions. The other parameters represent evolution of the response of the system and in particular $\alpha$ incorporates most of the modeling error since it is primarily responsible for the response shape, while $\tau$ strongly influences the response delay, and $\beta$ the amplitude of the response. Also note that unless Model I is used, the estimator will have more degrees of freedom than the actual number of parameters. This leads to an attempt to increase the accuracy of the parameter identification by using a two step estimator.

During the first stage, the complete filter is run on a data set (Model II has been chosen as an example), and for the second stage, the most strongly identified parameter from the first stage is held constant. From this, the degrees of freedom available are reduced and the other values may be estimated with greater precision. The steps for this process are outlined below:

1. Apply the estimator to Model II and obtain the intermediate parameters $\alpha, b$ and $c$. (Stage One)

2. Set the parameter with the best estimate constant and apply the filter again with the final values of the other parameters as initial conditions. (Stage Two)

3. From the final $b$ and $c$ compute $\beta$ and $\tau$.

To determine which parameter is to be held fixed at a constant value for the second stage of the estimation, an analysis of the final covariance matrix $\boldsymbol{P}$ must be performed. The parameter which corresponds to the smallest covariance at the end of the first stage of the estimation process is selected as having the highest confidence of identification.

\section{IN-WATER PARAMETER IDENTIFICATION EXPERIMENTS}

One of the main concerns addressed by this work is to design robust controllers for acceptable performance under wave conditions in shallow water. Several experiments were performed in order to obtain a model of the surge dynamics for ranges of frequencies of interest, namely some of the possible wave frequencies.

The in-water experiments were conducted in the NPS test tank by positioning the vehicle perpendicular to one of the tank wall about 10 feet away. Vertical and horizontal thrusters were under active control to maintain the vehicle at a depth of approximately 3 feet and perpendicular to the wall at all times. Continuously changing position commands from the wall consisting of sinusoids of a different frequency were used for each experimental data set. The propeller revolutions were measured by motor mounted tachometers. The surge velocity was measured indirectly by differentiating the position of the AUV relative to the wall face. The position was obtained by ultrasonic sonar measurements, and a Kalman filter was applied to the sonar ranges in order to obtain a clean estimate of position. Four data sets were generated for four different frequencies, (1) $f=0.5 \mathrm{rad} / \mathrm{sec}$, (2) $f=0.4 \mathrm{rad} / \mathrm{sec}$, (3) $f=0.7 \mathrm{rad} / \mathrm{sec}$, and (4) $f=0.2 \mathrm{rad} / \mathrm{sec}$. A three state Kalman filter was used for sonar signal filtering that at the frequencies of interest produce not only the estimation of position, but also the derivatives to give estimates of velocity and acceleration [13].

The use of the filter for obtaining $u(t)$ introduced new dynamics to the system, and if the values of $u(t)$ from filtering and $n(t)$ from the tachometer readings are used for parameter estimation, the sonar filter dynamics are introduced into the parameters. In order to minimize the influence of signal filtering and keeping in mind that the sonar filter has an almost unitary gain, the filter was also applied to the propeller speeds $n(t)$. From this, the same dynamics introduced in the $u(t)$ measurement path were also introduced for $n(t)$, and their overall effect on the model parameters sought should be minimal. 


\section{PARAMETER ESTIMATES FROM EXPERIMENTAL RESULTS}

In the estimators for all the identification models, the measurement noise covariance, $v$ was set to 0.01 , a constant scalar, and is the same value used by the sonar filter. The values of diagonal elements, $q_{i i}$, of the modeling noise covariance matrix $\boldsymbol{Q}$ were chosen in each case to match the bandwidth of input signal. With this choice, a tradeoff between good convergence, rapid stabilization of the filter, and precision of the estimates is made. The following results for each model type are for the "best" compromise of values selected for matrix $\boldsymbol{Q}$.

\section{A. Model I Results}

The first model design proved to be inadequate for describing the system since two of the data sets (2 and 3), predicted unstable values for the parameter $\alpha$. Table 1 shows the parameter estimation values obtained for each data set including statistics of the filter residuals $e$.

\begin{tabular}{ccccc}
\hline$q_{i i}=1.0$ & $\begin{array}{c}\text { Data } \\
\text { Set } \\
1\end{array}$ & $\begin{array}{c}\text { Data } \\
\text { Set } \\
2\end{array}$ & $\begin{array}{c}\text { Data } \\
\text { Set } \\
3\end{array}$ & $\begin{array}{c}\text { Data } \\
\text { Set } \\
4\end{array}$ \\
\hline$\alpha$ & -0.3626 & $* 1.295$ & $* 0.1895$ & -3.1120 \\
$\beta$ & 0.0024 & 0.0033 & 0.0028 & 0.0038 \\
\hline $\bar{e}$ & -0.1703 & - & - & 0.0134 \\
$\sigma_{e}$ & 0.3404 & - & - & 0.3496 \\
$|\bar{e}|$ & 0.2776 & - & - & 0.2834 \\
\hline
\end{tabular}

Table 1: Results for Model I - (*) Unstable Parameter.

Note: The units for the parameters are $\alpha[=] 1 / f t, \beta$ [=] $\mathrm{ft} / \mathrm{rev}^{2}$, and in the following tables, $\gamma$ [=] $1 / \mathrm{rev}, \tau[=] \mathrm{sec}$.

Figure 1-a shows the evolution of the parameter estimates and the diagonal elements of the covariance matrix $\boldsymbol{P}$ for data set 1. Figure 1-b is a comparison between the measured velocity $u(t)$ and the prediction from the model. Similar results were seen using the other three data sets as well. The noise in the evolution of the covariance matrix $\boldsymbol{P}$ is due to the rather large value of the diagonal elements of $\boldsymbol{Q}$. That was needed in this case, since smaller values lead to poor parameter estimates. The simplicity of the filter demanded an attempt to try to use the most of the measurements for the estimation process. Since
Model I failed to adequately describe the vehicle dynamics, a more sophisticated model, Model II was tried next.

\section{B. Model II Results}

All four data sets were run again using Model II, and the results are shown in Table 2.

\begin{tabular}{ccccc}
\hline$q_{i i}=1.0$ & $\begin{array}{c}\text { Data } \\
\text { Set } \\
1\end{array}$ & $\begin{array}{c}\text { Data } \\
\text { Set } \\
2\end{array}$ & $\begin{array}{c}\text { Data } \\
\text { Set } \\
3\end{array}$ & $\begin{array}{c}\text { Data } \\
\text { Set } \\
4\end{array}$ \\
\hline$\alpha$ & -0.7791 & -0.7066 & -1.5387 & -0.9144 \\
$\beta$ & 0.0016 & 0.0015 & 0.0017 & 0.0012 \\
$\tau$ & 0.7074 & 0.4544 & 0.5538 & 0.4486 \\
\hline $\bar{e}$ & -0.0863 & -0.0427 & -0.0023 & 0.0205 \\
$\sigma_{e}$ & 0.2173 & 0.1653 & 0.1854 & 0.1851 \\
$|\bar{e}|$ & 0.2009 & 0.1425 & 0.1597 & 0.1547 \\
\hline
\end{tabular}

Table 2: Results for Model II

The parameter evolution for data set 1 and the respective model simulation can be seen in Figures 2a and 2-b respectively. This filter/model had a much less noisy parameter evolution and a better description of the system than with Model I, as can be seen from the model response in both cases. This was not unexpected due to the limitations of Model I, since it had fewer parameters and the force lag was not modeled.

Figure 3 shows the coherence $C_{u e}$, along with a trace of the residuals $e$ through time, and from this analysis, it can be seen that the prediction errors are not white noise. From this, a bias is implicated in the estimation model and is probably caused mainly by the inherent inadequacy of the system model. Particularly, the error in the estimation of the lag response is mainly responsible for the non-whiteness of the residuals, (they exhibit a sinusoidal shape). This implies that there exists a phase lag and/or magnitude difference between the actual and predicted responses. However, it can be seen from the comparisons with the actual $u(t)$ that the predicted response is fairly close, and implies that although it has limitations, this model is of good use.

\section{Model III Results}

The results from the estimation with Model III are shown in Table 3. 


\begin{tabular}{ccccc}
\hline$q_{i i}=3.0$ & $\begin{array}{c}\text { Data } \\
\text { Set } \\
1\end{array}$ & $\begin{array}{c}\text { Data } \\
\text { Set } \\
2\end{array}$ & $\begin{array}{c}\text { Data } \\
\text { Set } \\
3\end{array}$ & $\begin{array}{c}\text { Data } \\
\text { Set } \\
4\end{array}$ \\
\hline$\alpha$ & -1.2359 & -1.6676 & -1.5980 & -1.6185 \\
$\beta$ & 0.0131 & 0.0132 & 0.0072 & 0.0019 \\
$\gamma$ & -0.1720 & -0.1204 & -0.0917 & -0.0917 \\
$\tau$ & 3.1413 & 2.8565 & 1.1329 & 0.6856 \\
\hline $\bar{e}$ & -0.1221 & -0.0551 & -0.0086 & 0.0089 \\
$\sigma_{e}$ & 0.2213 & 0.1946 & 0.2709 & 0.2673 \\
$|\bar{e}|$ & 0.1622 & 0.2263 & 0.1597 & 0.2264 \\
\hline
\end{tabular}

Table 3: Results for Model III

In the case of this model, we chose a slightly higher value for the model noise covariance than in Model II. This was due to the necessity of leaving some extra freedom for the filter. Since in this case there is not only a new parameter that in principle gives a better model and less freedom in the filter dynamics, but also an extra cross-coupling term that that introduces uncertainty in the model. A slight increase in the diagonal elements of $\boldsymbol{P}$ is noted in Figure 4 corresponding to the lag time constant $\tau$, which implies that the filter was not able to estimate $\tau$ with the same precision than in the previous case. In fact, this particular value of the dynamic noise covariance was selected as the limit for filter stability. Higher values of the covariance resulted in instability in the estimate of $\tau$ and lower values caused slightly worse estimates.

Comparing the residuals shown in Figure 6 with the previous cases, we see that they are more white in Model III (although yet very far from being white noise). The increased descriptive capability of the model is mostly responsible for this.

\section{Two-Stage Estimation Using Model II}

As an improvement to the one step estimation of the parameters for Model II, a second estimator was applied to the data with one parameter fixed. From the analysis of the matrix $\boldsymbol{P}$, it was concluded that the parameter with the least covariance was $b$ which was in accordance with physical insight. So this parameter was set to the value found previously, and the term $h_{4} C_{4}$ was incorporated into the measurement. This lead to a 3 parameter estimator although the cross term $\alpha c$ remained. The modeling noise covariance was set to a particularly low value since in this case one good estimate was available that was used as the initial value. Table 4 lists the results obtained from the four sets of data.

\begin{tabular}{ccccc}
\hline & $\begin{array}{c}\text { Data } \\
\text { Set }\end{array}$ & $\begin{array}{c}\text { Data } \\
\text { Set } \\
1\end{array}$ & $\begin{array}{c}\text { Data } \\
\text { Set } \\
3\end{array}$ & $\begin{array}{c}\text { Data } \\
\text { Set } \\
\end{array}$ \\
\hline & $q_{i i}=$ & $q_{i i}=$ & $q_{i i}=$ & $q_{i i}=$ \\
& 0.0032 & 0.0032 & 0.005 & 1.0 \\
\hline$\alpha$ & -0.5823 & -0.7066 & -1.3678 & -0.7968 \\
$\beta$ & 0.0022 & 0.0015 & 0.0022 & 0.0014 \\
$\tau$ & 0.9482 & 0.4544 & 0.7112 & 0.5075 \\
\hline $\bar{e}$ & -0.1275 & -0.0427 & -0.0035 & 0.0236 \\
$\sigma_{e}$ & 0.1633 & 0.1653 & 0.1673 & 0.1717 \\
$|\bar{e}|$ & 0.1718 & 0.1425 & 0.1444 & 0.1433 \\
\hline
\end{tabular}

Table 4: Results for Model II with Second Step and $b$ Constant.

The evolution of the two-stage filter can be seen in Figure 7-a and the error analysis in Figure 8. Comparing the results with the one step estimation for Model II, a slight improvement in the whiteness of the residuals is evident from the lower values of the coherence at lower frequencies as shown in Figure 8. Comparing with Model III, the results give less satisfactory responses, and in particular, the residuals are fairly correlated with the inputs. However, in this model two less parameters are present.

\section{COMPARATIVE ANALYSIS}

Analysis of the four data sets showed that data set 4 corresponded to the lowest frequency applied to the thrusters, but there were spikes in the tachometer readings that caused the actual signal $n(t)$ to not be a single frequency sinusoid. In fact, $n(t)$ was the base sinusoid with some higher frequency noise. For this data set, the frequency content was much greater than in the others and that was reflected in the estimation. Using an input signal with large frequency content is not bad in its itself, in fact, it excites more modes of the system and thus gives a better description. However, since the model is simplified, an attempt to model the behavior of the system for all possible frequencies is very difficult. So a tradeoff must be made between generality and applicability.

The comparison figures presented relate each model with the data used for their parameter estimation. A more useful comparison would be to check the performance of the model against other data sets. As an example, the response using the parameters from data set 1 when the input is obtained from the other data sets is shown in Figures 9, 10, 
and 11. From the comparisons it can be seen that Model III achieves the best results, however for input signals with very narrow bandwidth, Model II with two-stage estimation can also give good results, and in particular we see that in data set 3 that was the best model. The extra parameters in Model III allow it to model more accurately the shape of the response for cases when the frequency content is more complex. Depending on the input signal, it can be sufficient to use Model II with a two-stage estimation. However, this has implementation considerations since it requires extra computational time.

A comparison was also made between the Kalman filter estimator with a simple least squares fit model and with the response of a linear model in $u(t)$ and $n(t)$ with a similar number of parameters given by

$$
\begin{aligned}
u_{k+1}= & a_{1} u_{k}+a_{2} u_{k-1}+b_{1} n_{k} . \\
& +b_{2} n_{k-1}
\end{aligned}
$$

Figure 12 shows the comparison of Model II responses obtained by the Kalman filter, the least squares estimation, and the linear model (23). The least squares estimator (LSE) provided results similar to those obtained by the Kalman filter, but the latter produced a more accurate model (note the response of the high frequency perturbations on the peaks of $u(t))$. This was expected since the Kalman filter can be used to determine the least squares fit. The preference for its use is the ability to incorporate noise modeling in the identification process. The LSE when the noise is white and Gaussian always gives the best linear fit, but does not have the flexibility of the Kalman filter. Moreover, it is easier to tune the identification process in the latter with a priori knowledge of the system. The linear model, as expected, provided poorer results than the non-linear one, particularly in the description of the higher frequency content of the signal.

In general, Model III gave the best results since it was more complex, however it can be seen from sets 2 and 3, Model II with the two-stage estimation provided some good results. When comparing each model obtained from each data set with the others (not shown here), it is concluded that data set 1 provides more general models. Therefore, for simulation purposes the parameters of Model III obtained from data set 1 should be used to model the longitudinal dynamics of the vehicle. In fact these values agree with observations of the vehicle performance in the open water.

\section{CONCLUSIONS}

In this paper, an initial work was presented towards the development of models suited for the experimental determination of the longitudinal dynamics of an AUV and methods for the parameter estimation for the above models. The model of a particular vehicle (NPS Phoenix AUV) was identified from in-water test tank experiments. The comparative analysis given showed the necessity of non-linear dynamic modeling and of the inclusion of a force lag term. The results obtained are satisfactory, in particular for the frequencies of interest, although the residuals appeared to be non-white. The nonwhiteness of the residuals indicates the lack of modeling capability, which was not unusual considering additive measurement noise was present and causes a bias in the linear estimates. When using the LSE, the noise is not white and equivalently in the Kalman filter, the measurement dynamics model is corrupted by unmodeled noise. However, it must be stressed that simple models for particular applications are useful.

One interesting fact discovered using the Kalman filter estimator was that taking $\boldsymbol{Q}$ as a diagonal matrix with all values equal, produced better estimates in the sense that the residuals were minimized and the filter lead to stable parameter evolution. This reflected a priori, equal certainty of each initial parameter estimation. Moreover, the interrelationships between the parameters (crosscoupling) implied a uniform characterization of the modeling noise in the estimation filter. The tuning of the estimation filter proved to be an important step towards obtaining a good model.

The two-stage estimation process resulted in a relevant improvement versus the single stage model and in some cases presented results comparable with higher order models. In future work this technique can be extended to other cases, applied to higher order models and is of particular usefulness for the improvement of already existent estimates with different degrees of certainty.

Model III, the four parameter non-linear model provided the best results. Fortunately, this model is simple enough for real-time application and provides reasonable responses for the input signals of interest. For future work, the development of more complex models and their experimental validation must be performed. In particular, there is the necessity of at sea experiments in order to gain further knowledge of the modeling necessities. In particular wave conditions, as in shallow water or near surface 
operation can introduce important changes to the dynamics that must be accounted for.

Finally, the methodology presented can be extended to other types of vehicle motions and represents a first step to the development of models and identification techniques for coupled motion that will be present while operating in shallow waters.

\section{AKNOWLEDGMENT}

The authors wish to recognize the financial support of Dr. Kam $\mathrm{Ng}$ from the Office of Naval Research under grant No. N001496WR20037. It is also desired to acknowledge the support of Alfredo Martins from the University of Porto, Portugal.

\section{REFERENCES}

[1] Fossen, T., "Nonlinear Modeling and Control of Underwater Vehicles", Dr. Ing. Thesis, Norwegian Institute of Technology, Trondheim, 1991.

[2] Fossen, T., Guidance and Control of Ocean Vehicles, John Wiley \& Sons, 1994.

[3] Healey, A., and Lienard, D., "Multivariable Sliding Mode Control for Autonomous Diving and Steering of Unmanned Underwater Vehicles, IEEE Journal of Ocean Eng., vol. 18, no. 13, 1993.

[4] Marco, D., and Healey, A., "Sliding Mode Acoustic Servoing for an Autonomous Underwater Vehicle", 24th Offshore Technology Conference, Houston, Texas, 1992.

[5] Healey, A., and Marco, D., "Slow Speed Flight Control of Autonomous Underwater Vehicles: Experimental Results with the NPS AUV II", Proc. 2nd Int. Offshore and Polar Engineering Conference (ISOPE), San Francisco, CA, 1992.

[6] Cristi, R., Papoulias, F., and Healey, A., "Adaptive Sliding Mode Control of Autonomous Underwater Vehicles in the Dive Plane", IEEE Journal of Ocean Eng., vol. 15, no. 3, 1990.

[7] Healey, A., "Marine Vehicle Dynamics Lecture Notes and Problem Sets", Naval Postgraduate School (NPS), Monterey, CA, 1996.

[8] Yoerger, D., Cooke, J., and Slotine, J., "The Influence of Thruster Dynamics on Underwater Vehicle Behavior and Their Incorporation into
Control System Design", IEEE Journal Oceanic Eng., vol. 15, no. 3, July 1990.

[9] McLean, M., "Dynamic Performance of Small Diameter Tunnel Thrusters", M.S. Thesis, Naval Postgraduate School, Monterey, CA, 1991.

[10]Brown, J., "Four Quadrant Dynamic Model of the AUV II Thruster", M.S. Thesis, Naval Postgraduate School, Monterey, CA, 1993.

[11]Ljung, L., System Identification: Theory for the User, Prentice Hall Inc, Englewood Cliffs, NJ, 1987.

[12] Gelb, A., Applied Optimal Estimation, M.I.T. Press, Cambridge, MA, 1989.

[13] Marco, D., “Autonomous Control of Underwater Vehicles and Local Area Maneuvering”, Ph.D. Thesis, Naval Postgraduate School, Monterey, CA, 1996. 

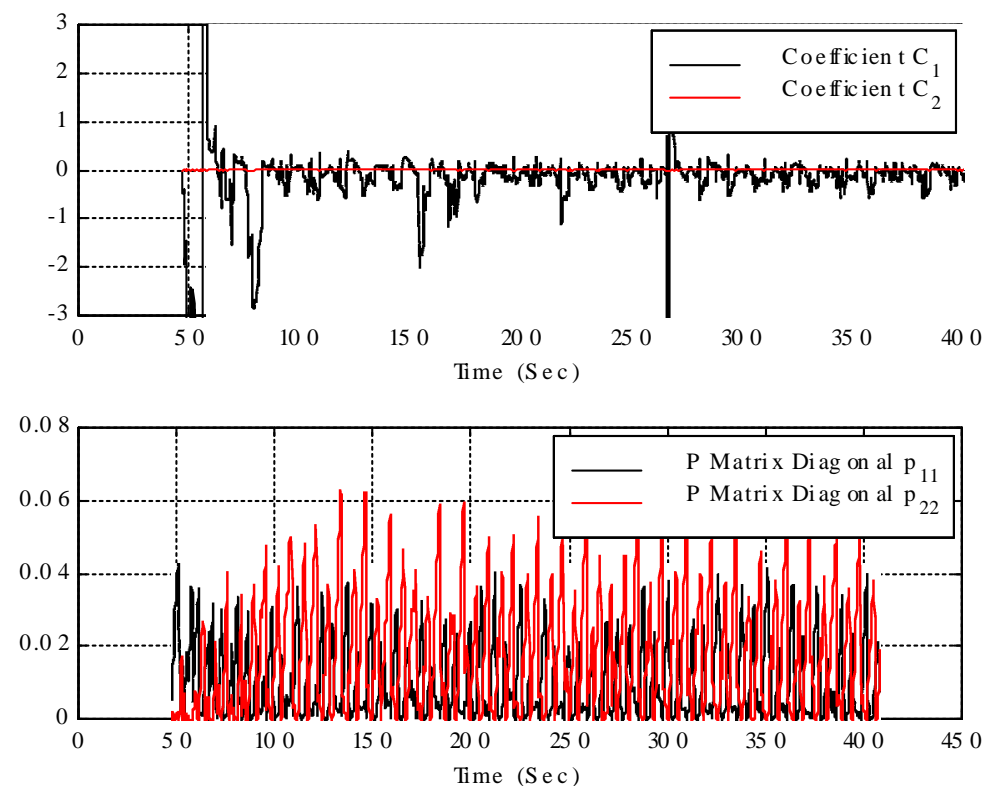

Figure 1-a. Parameter evolution for Model I (Data set 1).

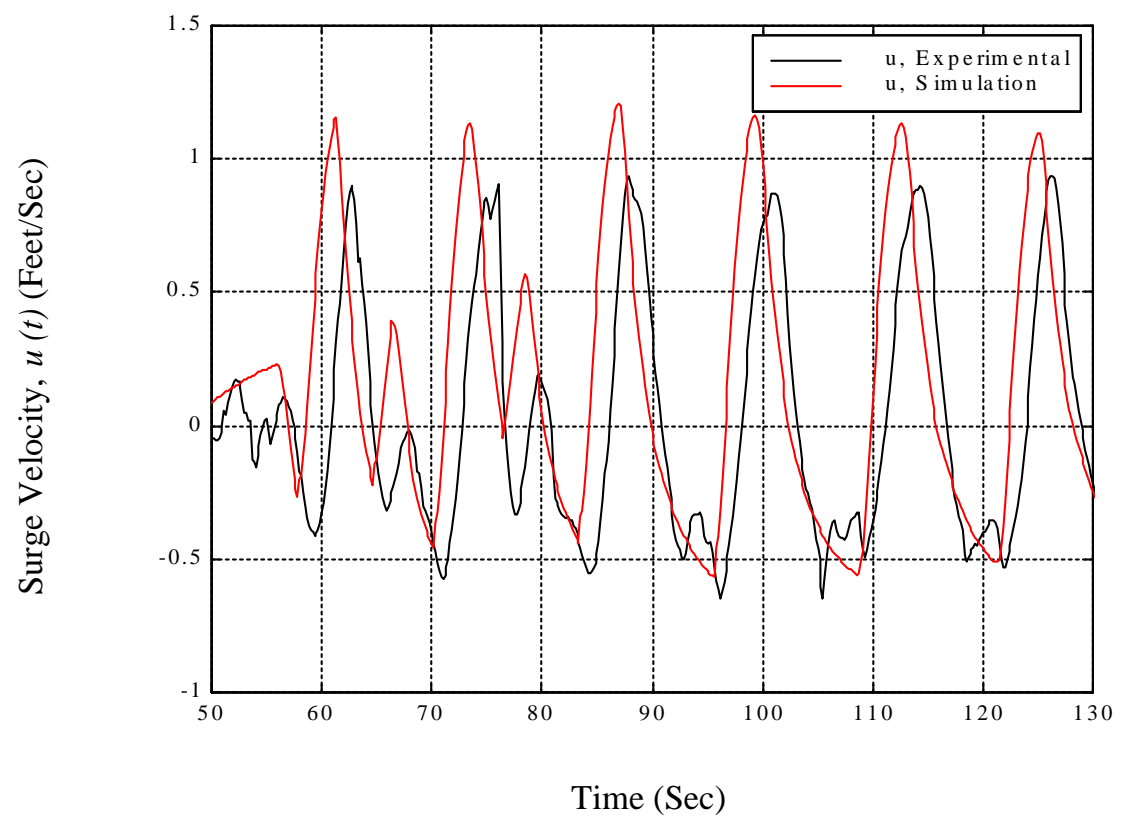

Figure 1-b. Model comparison for Model I (Data set 1). 

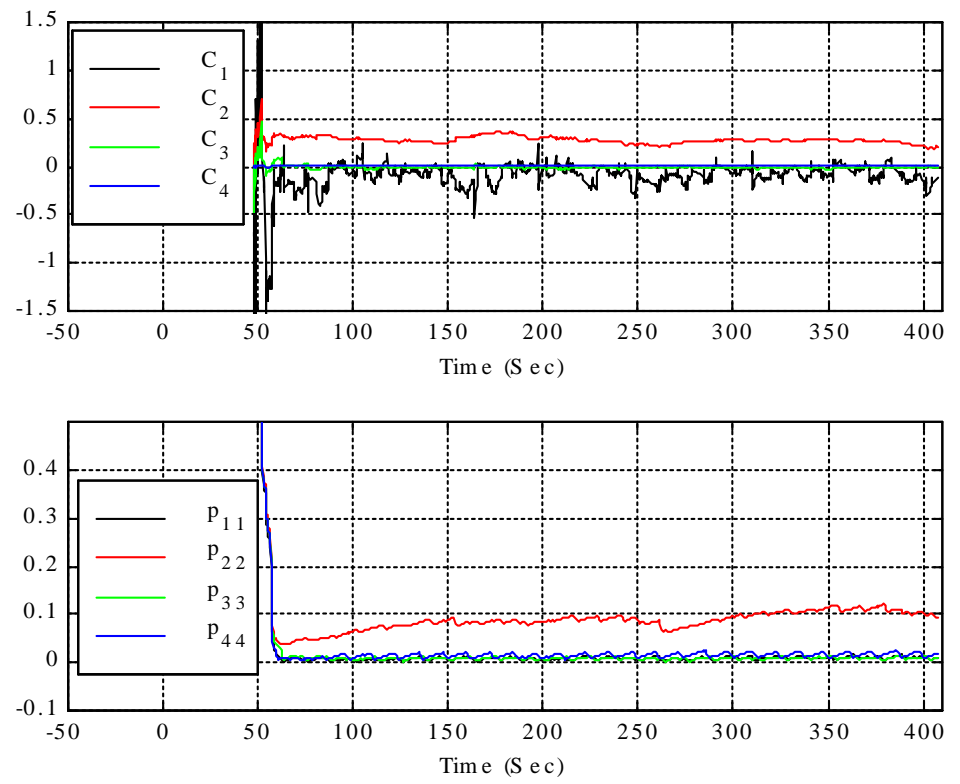

Figure 2-a. Parameter evolution Model II (Data set 1).

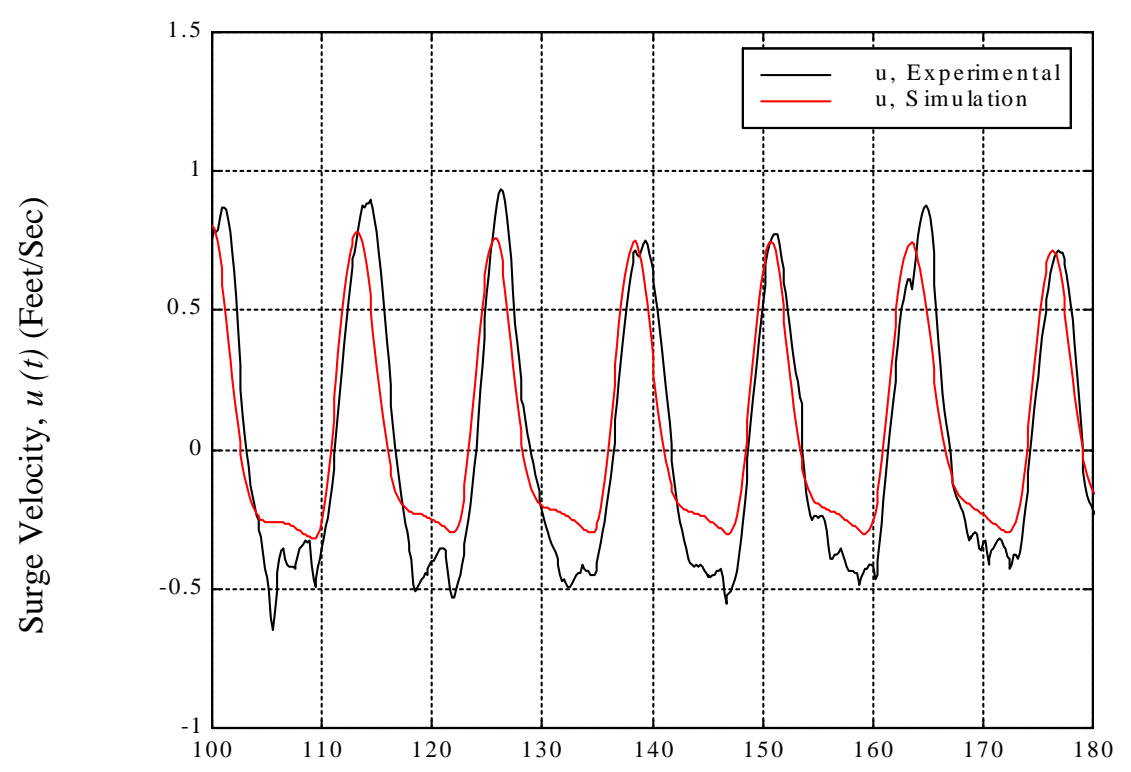

Time (Sec)

Figure 2-b. Model comparison for Model II (Data set 1). 

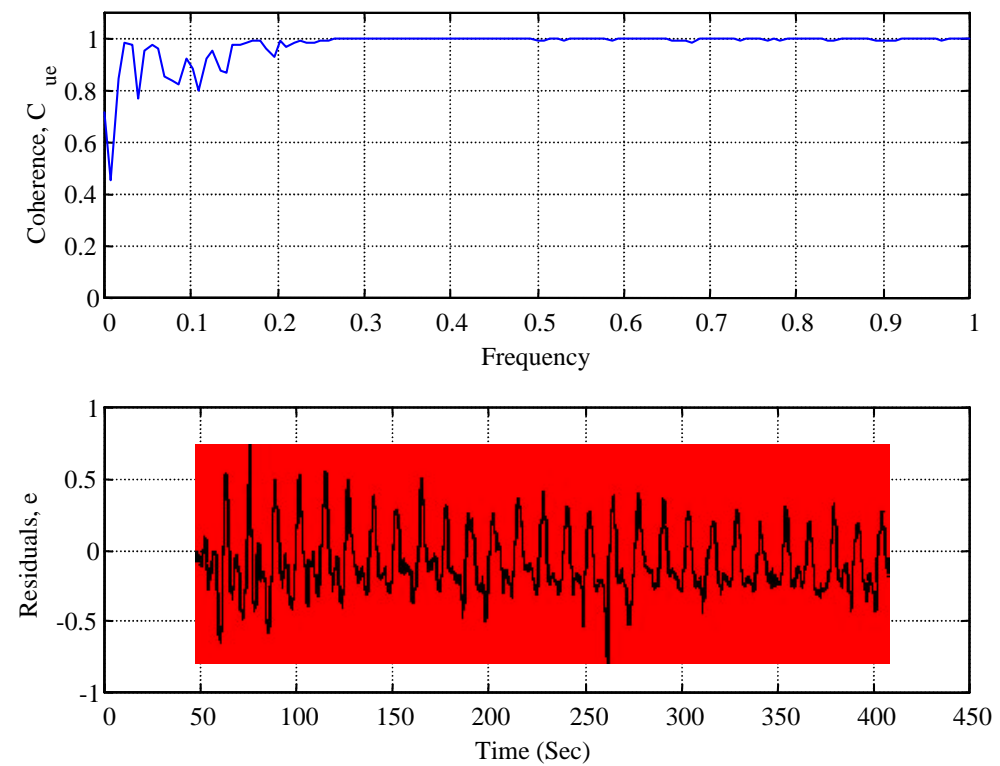

Figure 3. Coherence between $u(t)$ and residuals (top) and plot of residuals (bottom) for Model II (Data set 1).
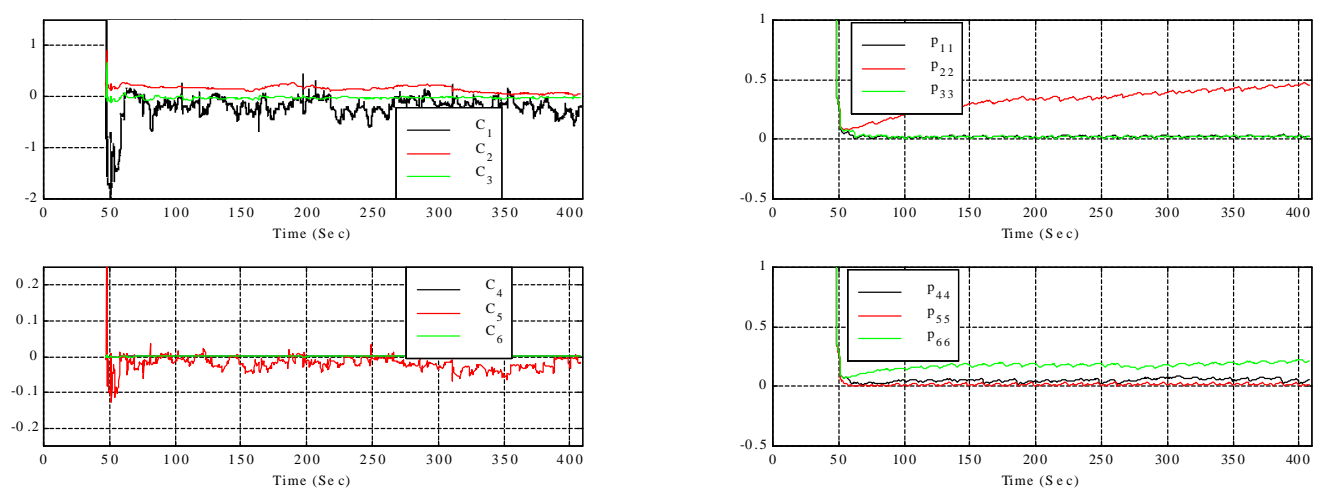

Figure 4. Parameter evolution for Model III (Data set 1). 


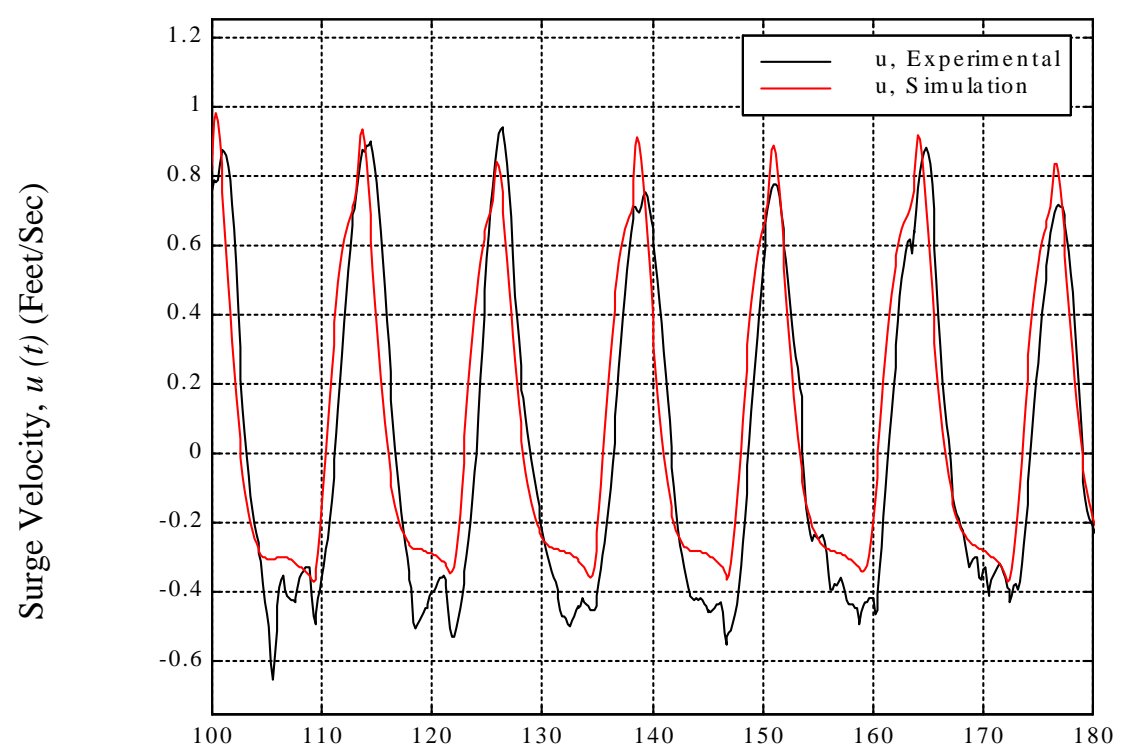

Time $(\mathrm{Sec})$

Figure 5. Model comparison for Model III.
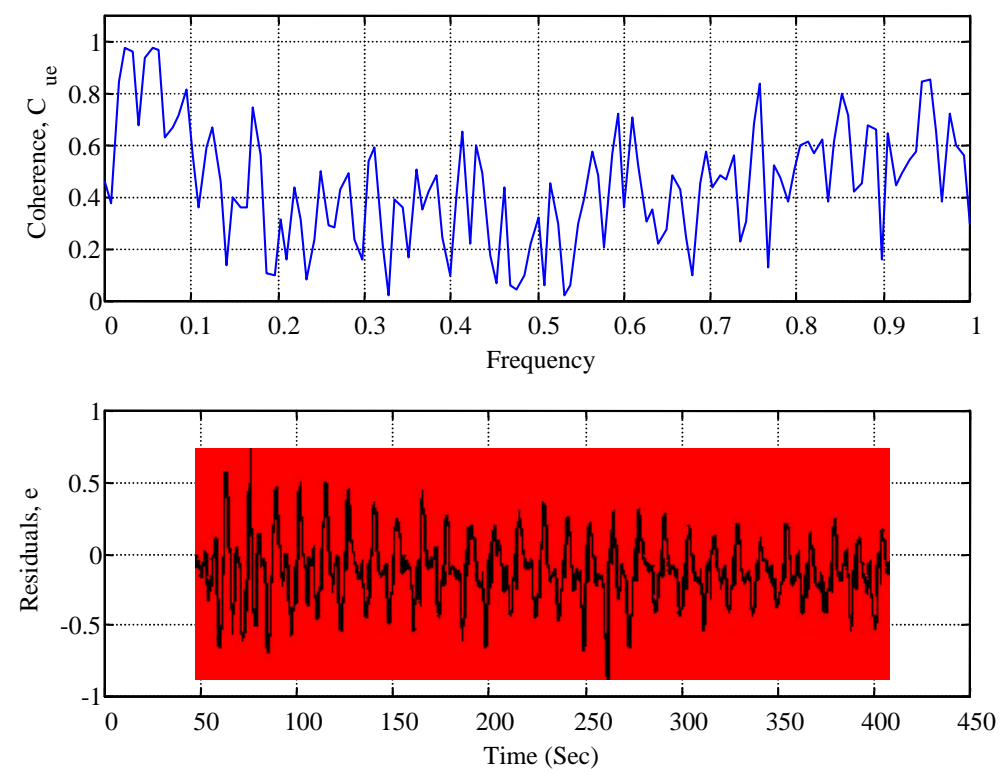

Figure 6. Coherence between $u(t)$ and (Data set 1) residuals (top) and plot of residuals (bottom) for Model III (Data set 1). 

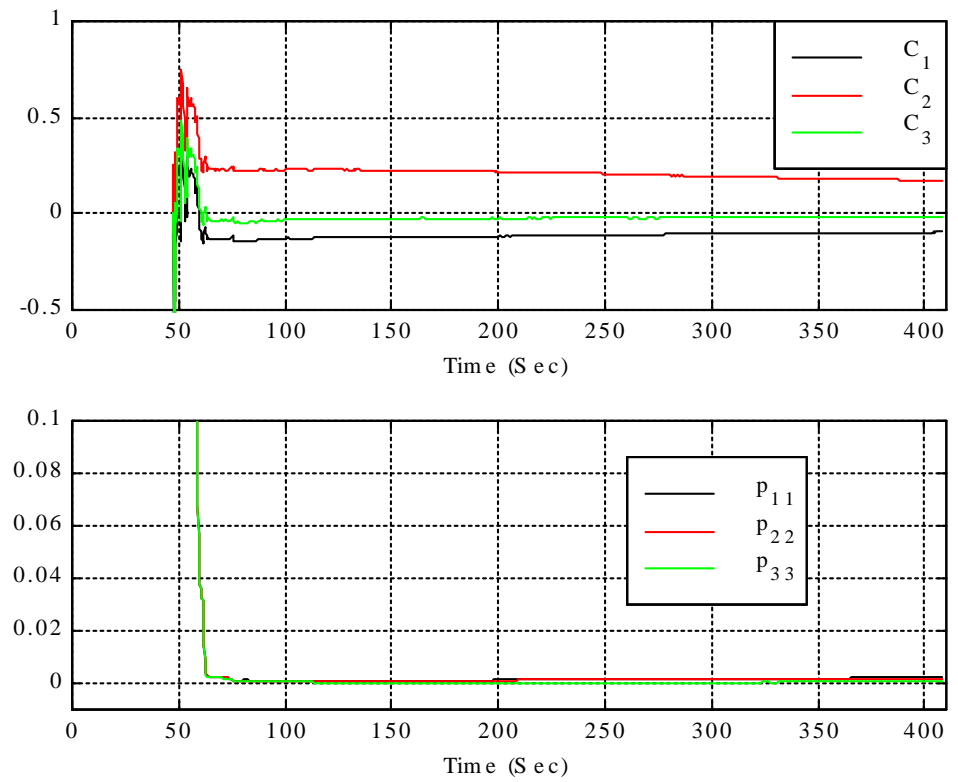

Figure 7-a. Parameter evolution for Model II (Data set 1) using two-stage estimation with $b$ constant.

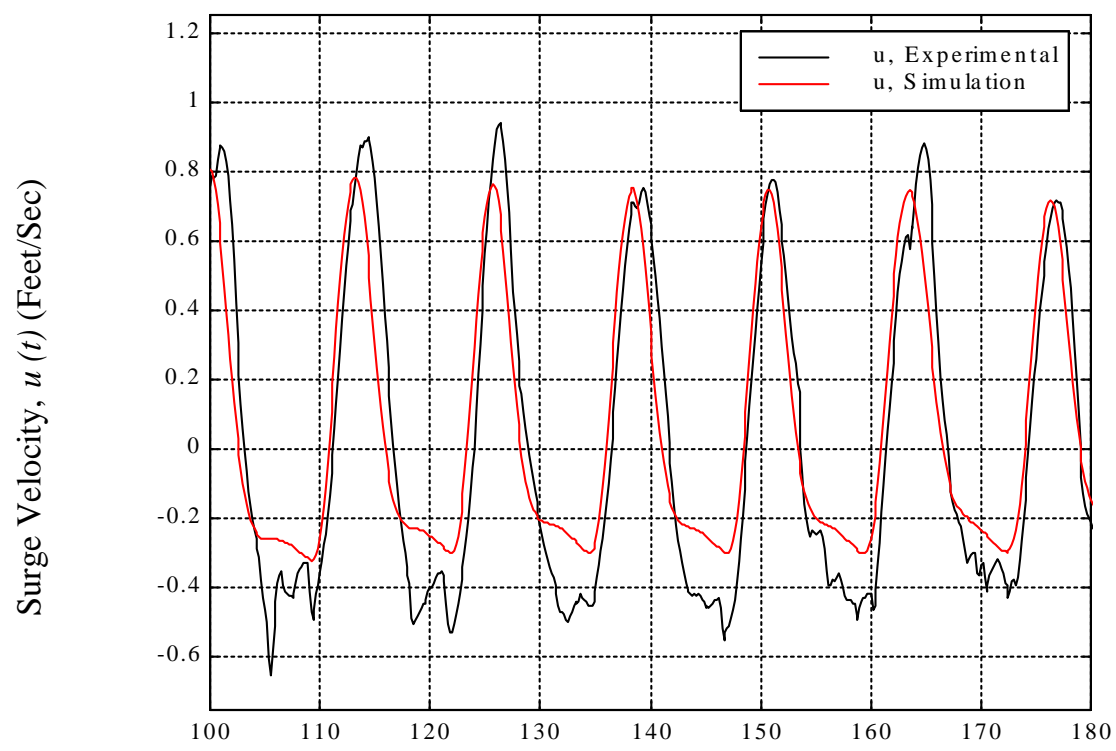

Time $(\mathrm{Sec})$

Figure 7-b. Model comparison for Model II (Data set 1) using two-stage estimation with $b$ constant. 

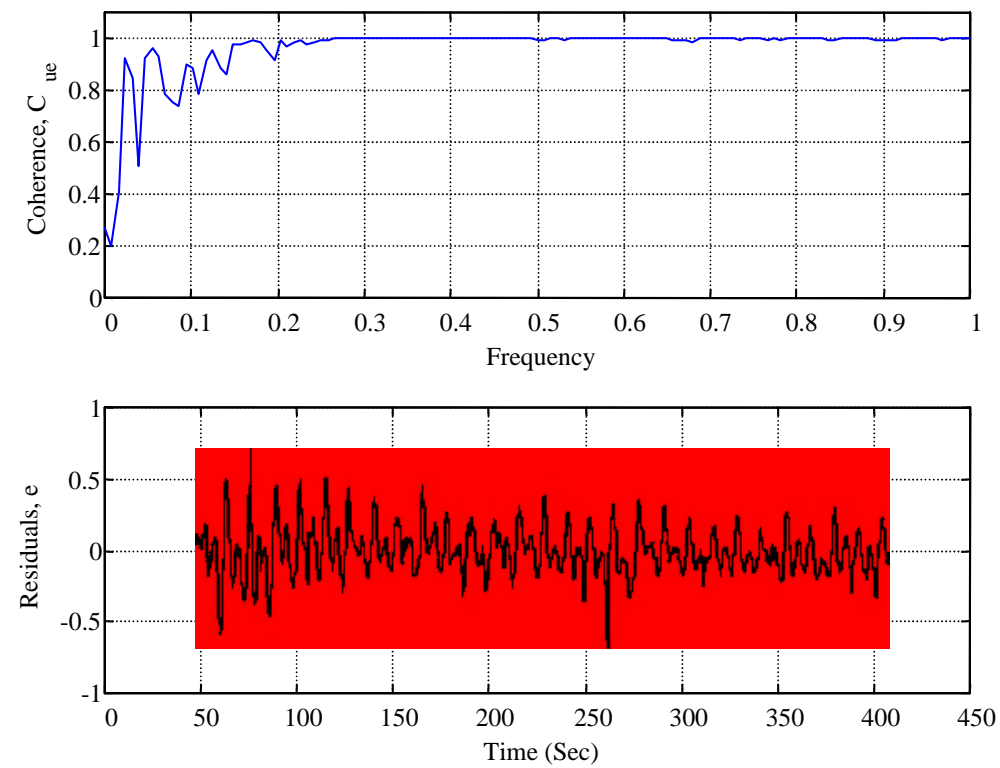

Figure 8. Coherence between $u(t)$ and residuals (top) and plot of residuals (bottom) for Model II (Data set 1) using two-stage estimation with $b$ constant.

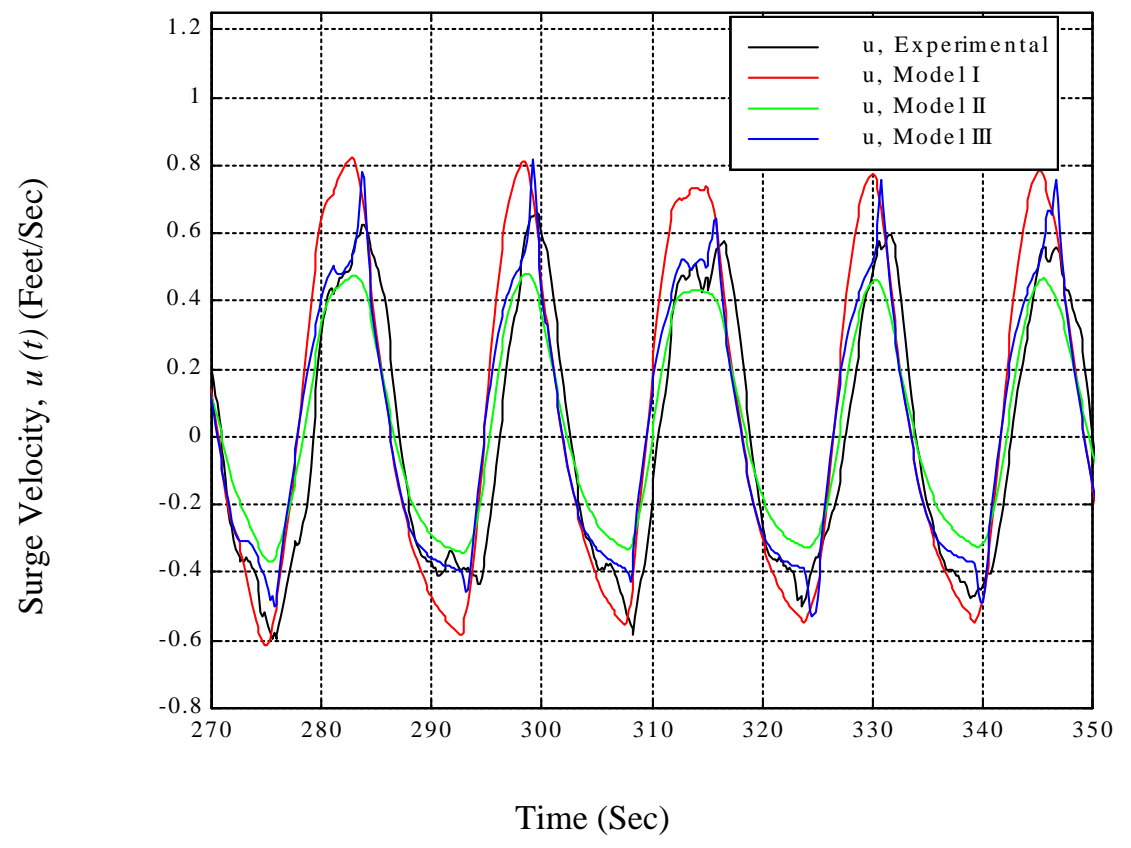

Figure 9-a. Comparison between models derived from data set 1 against data set 2. 


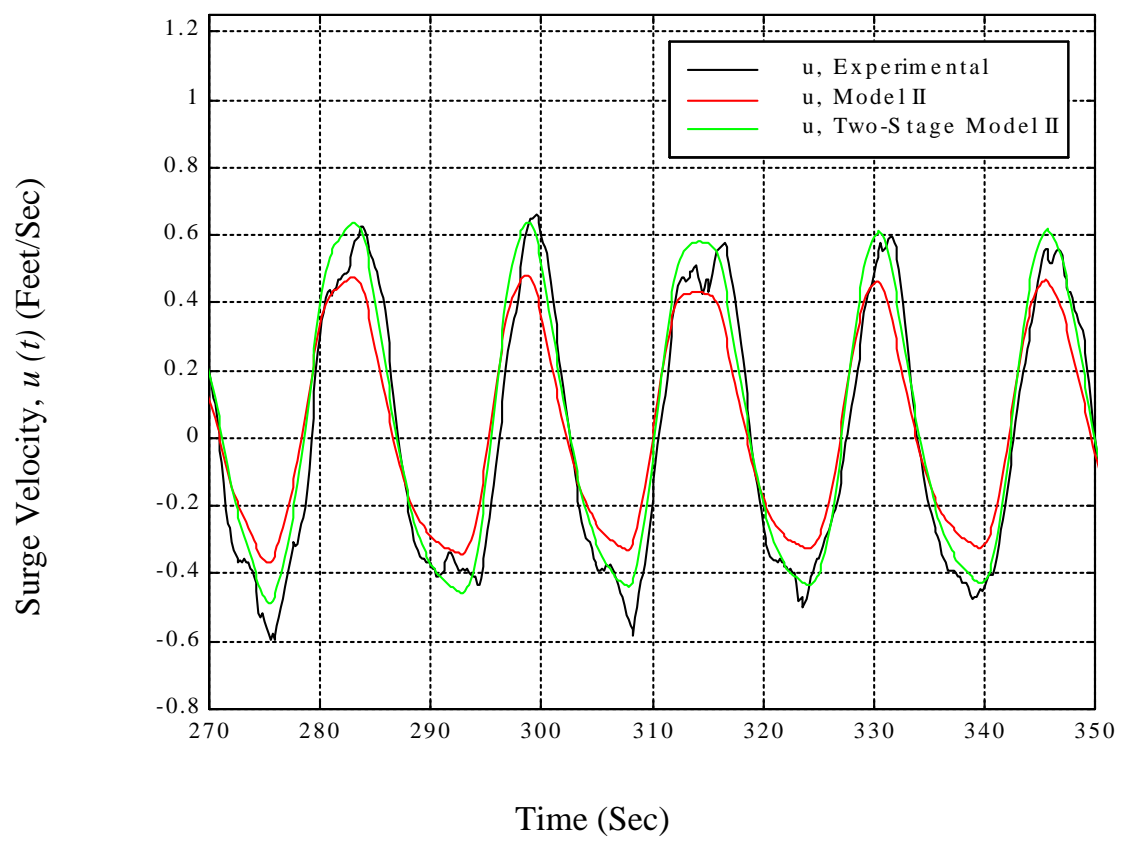

Figure 9-b. One stage vs. two-stage Model II (Data set 2).

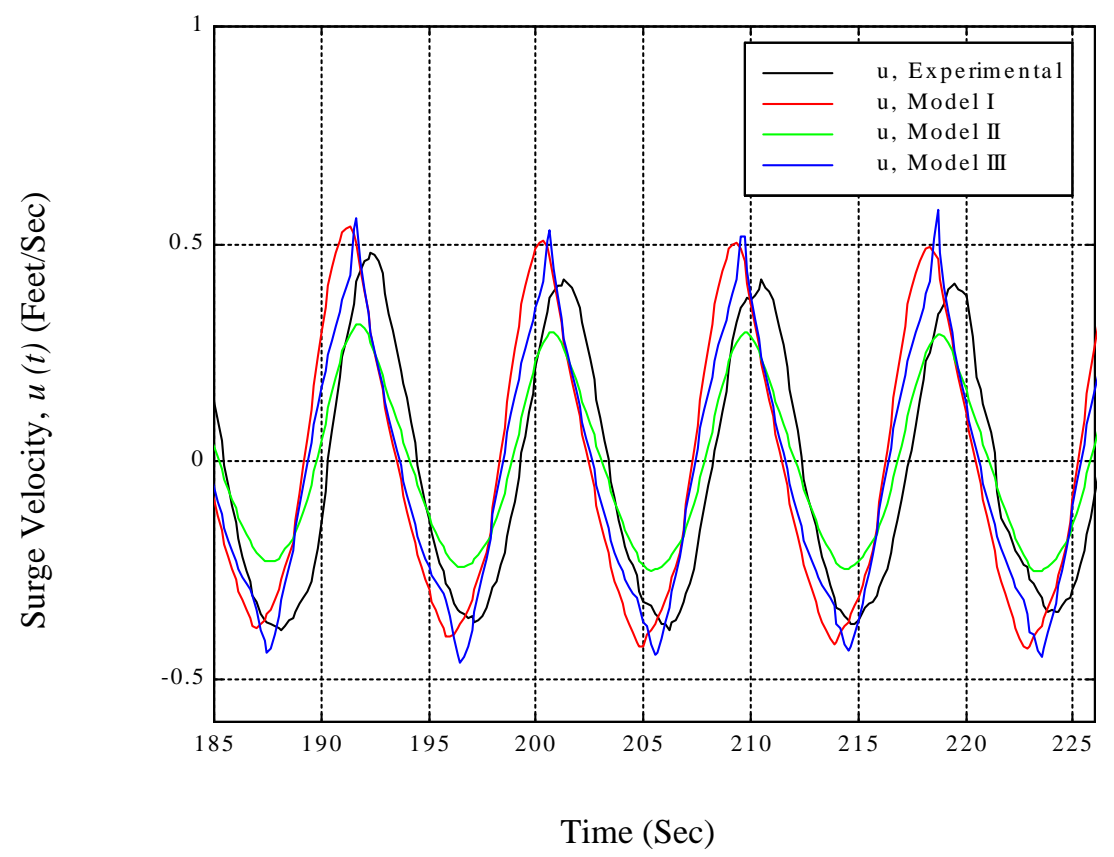

Figure 10-a. Comparison between models derived from data set 1 against data set 3 . 


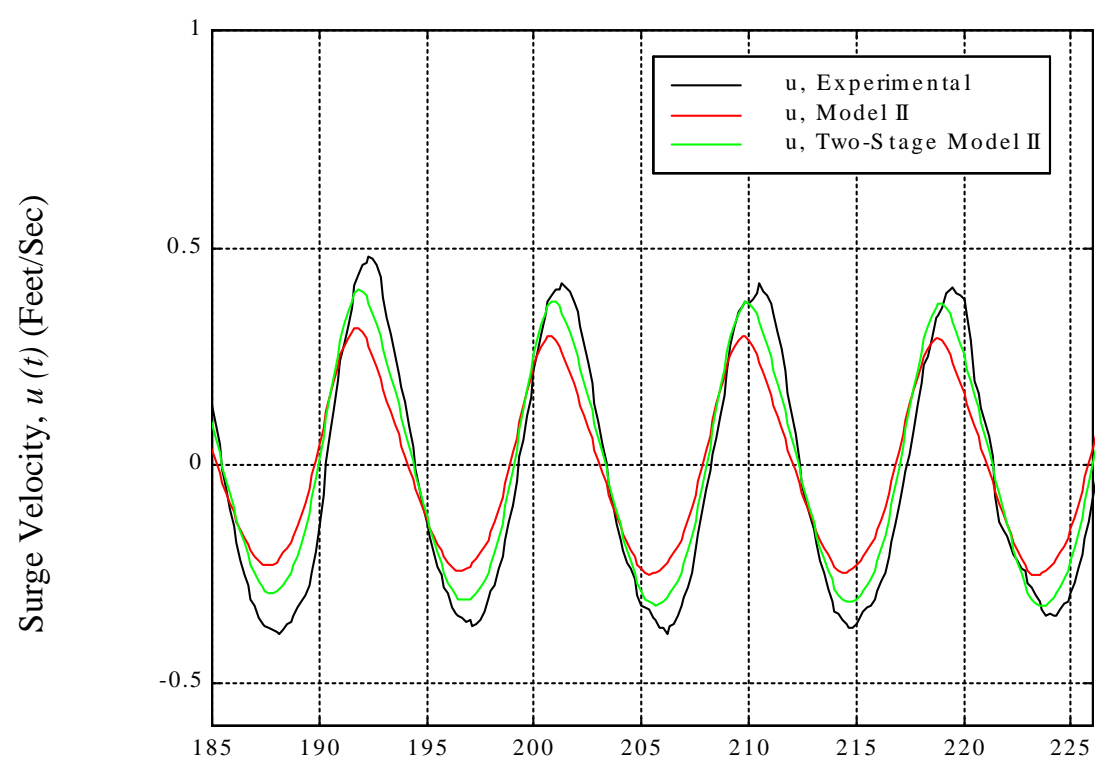

Time (Sec)

Figure 10-b. One stage vs. two-stage Model II (Data set 3).

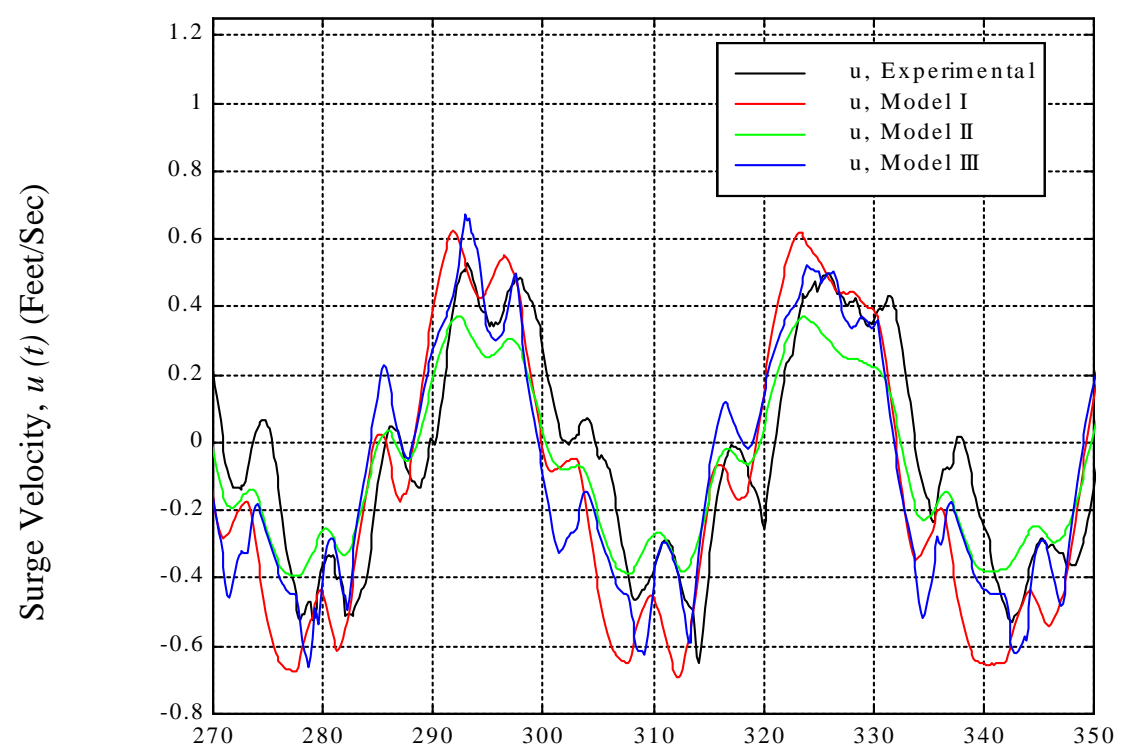

Time (Sec)

Figure 11-a. Comparison between models derived from data set 1 against data set 4 . 


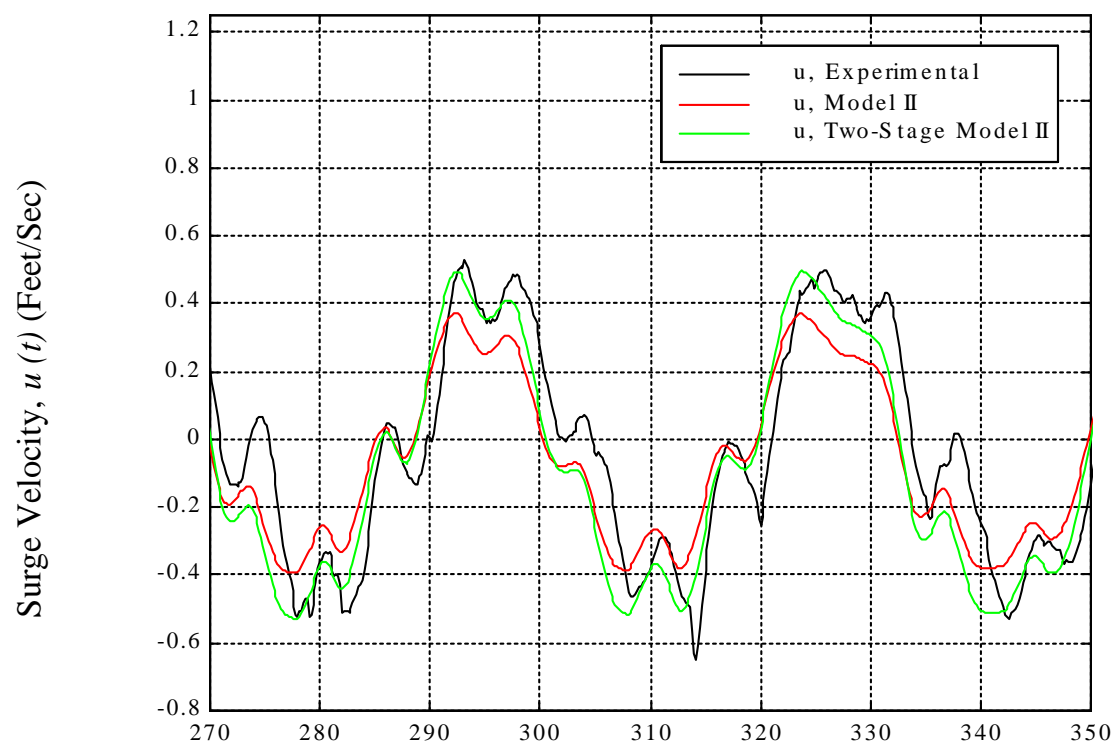

Time (Sec)

Figure 11-b. One stage vs. two-stage Model II (Data set 4).

Figure 12. Comparison between linear model, LSE, and two-stage Kalman filter for data set 2. 